\title{
Use of Software on Modeling Hazardous Substance Release as a Support Tool for Crisis Management
}

\author{
Maria Polorecka ${ }^{1}$, Jozef Kubas ${ }^{2, *(D)}$, Pavel Danihelka ${ }^{3}$, Katarina Petrlova ${ }^{4}$, Katarina Repkova Stofkova 5 \\ and Katarina Buganova ${ }^{2}$
}

check for

updates

Citation: Polorecka, M.; Kubas, J.; Danihelka, P.; Petrlova, K.; Repkova Stofkova, K.; Buganova, K. Use of Software on Modeling Hazardous Substance Release as a Support Tool for Crisis Management. Sustainability 2021, 13, 438. https://doi.org/ $10.3390 /$ su13010438

Received: 14 November 2020

Accepted: 3 January 2021

Published: 5 January 2021

Publisher's Note: MDPI stays neutral with regard to jurisdictional clai$\mathrm{ms}$ in published maps and institutional affiliations.

Copyright: (C) 2021 by the authors. Licensee MDPI, Basel, Switzerland. This article is an open access article distributed under the terms and conditions of the Creative Commons Attribution (CC BY) license (https:// creativecommons.org/licenses/by/ $4.0 /)$.
1 Department of Fire Engineering, Faculty of Security Engineering, University of Žilina, 01026 Žilina, Slovakia; Maria.Polorecka@fbi.uniza.sk

2 Department of Crisis Management, Faculty of Security Engineering, University of Žilina, 01026 Žilina, Slovakia; Katarina.Buganova@fbi.uniza.sk

3 VSB-Technical University of Ostrava, 70800 Ostrava-Poruba, Czech Republic; Pavel.Danihelka@vsb.cz

4 Mathematical Institute in Opava, Silesian University in Opava, 74601 Opava, Czech Republic; Katarina.Petrlova@math.slu.cz

5 Department of Communication, Faculty of Operation and Economics of Transport and Communication, University of Žilina, 01026 Žilina, Slovakia; Katarina.Stofkova@fpedas.uniza.sk

* Correspondence: Jozef.Kubas@fbi.uniza.sk; Tel.: +42-141-513-6705

\begin{abstract}
Today's modern society offers many new opportunities, but also many risks. Even modernization of companies cannot completely eliminate these dangers. In the smart industry, despite significant technological progress, it is necessary to work with various raw materials, including hazardous substances. It is these raw materials that will continue to pose risks in the future for industrial accidents, which cannot be ruled out. The possible release of hazardous substances can potentially have a negative impact on the environment and safety of the population. In order to deal with certain emergencies, it is necessary to allocate a large amount of funds and resources to them. The paper focuses on risk prevention in industry and the use of modern and new approaches. Specifically, it focuses on the implementation of the prevention of leakage of hazardous substances in the gaseous state from industrial facilities. The aim of the paper is to present a new approach to the prevention of leakage of hazardous substances, which provides more realistic calculations for modeling leaks and thus helps to reduce the cost of prevention. However, security in crisis management is not diminished. ALOHA CAMEO software was used for leak modeling, which the authors commonly use in practical applications and modeling in industrial enterprises in the performance of duties in the field of civil protection and crisis management. ALOHA software is used for such modeling, serving as a support tool for modeling for all crisis managers in Industry 4.0. This paper deals with the modeling of dispersion of hazardous substances with specific properties escaping from technological equipment located inside a building. This concerns the inability of the current dispersion model software to prevent the spread of the next leak inside the building containing the substance. A solution is needed to fix this problem. This issue is well illustrated by a specific example at the end of this article. The mentioned improvement of tools for simulation of industrial accidents influences the possibilities of development also in Industry 4.0. It enables more effective preparation for the management of possible accidents with regard to the appropriate spending of funds for prevention and subsequent response.
\end{abstract}

Keywords: ALOHA (software); ammonia; dispersion; hazardous substance release; Industry 4; crisis management

\section{Introduction}

The Fourth Industrial Revolution is changing the current form of industry both in Slovakia and around the world. This process was given different names throughout the world, e.g., Industry 4.0 in Germany, New Industrial France in France, the National 
Network for Manufacturing Innovation in the USA, Society 5.0 in Japan, and Made in China 2025 in China, etc. [1].

Industry 4.0 provides economic, environmental, and social benefits and opportunities [2]. The implementation of automation and digital production, digitization of control systems and the use of communication networks to ensure interoperability and flexibility of business processes is becoming a priority for the industry. Thanks to the Internet, which will become an integral part of industrial control systems, a high volume of exchanged data will be created, which results in functional analysis of big data, virtual process simulation, cloud connectivity, augmented reality, autonomous devices, and 3D printing. However, creating a sustainable industrial value requires that activities are implemented on the 3 pillars of social responsibility. The integration and combination of the economic, social, and environmental pillars is in line with the triple bottom line's concept of sustainability [3-5].

The economic dimension of sustainability focuses on economic performance, market presence, indirect economic impacts, and procurement practices. It is linked to the ecological dimension in relation to the use of energy and resources, and social dimension in relation to safeguarding and the creation of workplaces. The social dimension of sustainability focuses on providing equity and safety to employees, stakeholders, and the community in which they operate [6]. Balancing these three dimensions is a critical success factor for the successful adoption and diffusion of technologies, as well as for achieving sustainable benefits [7-9].

It is the extensive changes brought about by digitalization which are rapidly entering today's industrial enterprises that are characteristic of Industry 4.0. Digitization focuses mainly on process, technical and technological optimization with the aim of speeding up process activities, reducing data processing time, and improving the availability of information. Digitization as an ongoing convergence of the real and virtual worlds will be a major driver of innovation and change in all sectors of our economy. Thanks to the digital transformation to Industry 4.0, information technology, computer control, and communication networks, it is possible to collect huge amounts of data. These data on operating and process conditions are generated from several devices, and are collected for automatic fault detection and diagnosis to minimize downtime and increase component utilization, as well as increase their remaining life and the overall competitive advantage of the company [10-12].

The aim is to create fully digitized, networked, intelligent, and decentralized valueadded networks. Industrial companies should offer a higher return on investment while reducing environmental impact, whilst creating attractive workplaces for people focused on collaboration, learning, and skills development. The dynamic development of industrial digitization and telecommunications technologies enables for a better integration of processes, machines, employees, and individual products within intelligent network structures. Industry 4.0 enables data collection and analysis, productivity assessment, and continuous process improvement [13-15].

The development of an intelligent industry in the context of Industry 4.0, thus robotization and automation of processes in companies, will significantly increase the productivity and competitiveness of individual companies, but it can also be a source of new risks. All companies and institutions are responsible for the proper handling of hazardous materials in the course of their activities. This is where Industry 4.0 can provide an opportunity for the industry to minimize the risks and threats posed by their processes through a high degree of automation and digitization of those processes. Gobbo et al. [16], identified the potential links and benefits between process safety and environmental protection with Industry 4.0 concepts by measuring the co-occurrence of keywords, and concluded that there is much more joint research between environmental protection and Industry 4.0 than between Industry 4.0 and safety. Industry 4.0 is a comparatively new method of managing production processes. In the area of risk management, new types of risks may arise due to new approaches, modified frameworks, complex IT infrastructure, and the like. In many 
cases, the implementation of Industry 4.0, which connects people, systems, and the object, has become a complex, dynamic, and real-time optimized network [17].

Sustainability and competitiveness belong to the main goals of the philosophy of industrial engineering and Industry 4.0. The main characteristic of safety is resilience to all risks that threaten the future survival situation, and then their mitigation in order to achieve optimal use of resources in all respects. Elattar [18], in his research states that security metrics and adaptation methods are still lacking to support business operations. Almost all industrial companies adopt certain forms of procedures in the field of health and safety in the environment. However, there is no single framework or procedure to withstand losses due to a lack of safety measures, and it is essential that the used procedures complement each other. This would lead to the integrated application of traditional methodologies with the management of safety barriers, dynamic risk assessment, and the integration of machine learning systems. Therefore, companies are resorting to creating their own tailor-made security framework that will increase their resilience and maintain their competitiveness and sustainability. Companies must provide an overview of the safety deficiencies, failures, and losses they have suffered $[18,19]$. Based on the above, there is a direct link here, which points to the fact that increased security and risk resilience as crisis prevention is a prerequisite for increasing the competitiveness and sustainability of Industry 4.0 companies.

Information, analysis and assessment of hazards, vulnerabilities, and risks are key decision-makers in crisis management and should be provided to the greatest possible extent in all normal, emergency, and critical conditions. Likewise, in all preparatory and operational functional areas, measures are taken or should be taken to control hazards, vulnerabilities, and risks as much as possible, with the overall aim of strengthening the resilience of the process, company, system, community. Initial problems that can lead to catastrophic failures can be correctly predicted and appropriate steps can be taken to prevent these failures based on the results of the predictions if appropriate predictive maintenance approaches are used. At any time, the industrial equipment can be replaced or repaired before a failure occurs, which may mean restoring the equipment or system to its original state after each realized maintenance $[10,20]$.

Industry 4.0 can break trade-offs from older strategies by enabling companies to maximize the life of their manufacturing facilities while preventing unplanned downtime, minimizing planned downtime, increasing process, and human safety, minimizing energy and resource consumption, and saving costs [21].

Crisis management is a dynamic and continuous process that includes both proactive and reactive measures to identify the crisis, plan the response to the crisis, face the crisis, and resolve the crisis [22]. The authors [23,24], argue that the real challenge, however, is to identify crises in time and implement coping strategies to reduce their damage. Authors such as Burnett [25], Kash and Darling [26], note that pre-crisis decisions will allow for more effective crisis management than for organizations to manage the crisis and make hasty and ineffective decisions. Proactive planning through strategic planning and problem management will help reduce risk, waste of time, poor resource management, and reduce the impact of those that arise [27]. Authors suggest that developing processes to address future crises that arise is more effective than constantly looking for all potential impacts. Identifying the problem through environmental scanning and data collection on the political, economic, social, and technological environment can provide information about possible trends and their likely impacts on the organization [23,28].

More authors describe two basic approaches to crisis management, which are also applicable in the context of Industry 4.0. They describe crisis management in the narrower sense only as a response to unexpected crises and in a broader sense (comprehensive approach) as a prevention too. Prevention begins with situational analysis, identification and risk assessment, and the preparation and implementation of measures to mitigate them and increase the resilience of the company. Prevention can be implemented through risk management [29-31]. The overall objective is to mitigate the risks associated with hazards 
in a way that is relevant to potentially affected people, real estate, local infrastructure, critical infrastructure, and critical functions. Operational functions are divided into three areas: protection, response, and recovery. In the context of crisis management, critical resilience capability is the ability at all levels of command and control to maintain consciousness in a very complex, dynamic, and harmful situation, make relevant and timely decisions and communicate, manage their implementation and operations, and quickly restore disrupted vital system functions. The primary outcome of safety management is a safe environment for emergency responders, equipment, and supplies involved in crisis management operations. Functions and tasks are defined in terms of planning, organizing, and building capabilities for security and security management [32,33].

Crisis management planning is, in fact, complementary to the development of risk management strategies (if they fail for any reason) and mainly concerns the readiness to react reactively when a crisis occurs, to include its impact and then to recover from it as soon as possible. Therefore, risk and crisis management are not two separate functions, but rather two complementary phases of the same learning-based function, which are aimed at developing the organization's ability to face adverse and disruption without consequences or with limited consequences and to recover quickly from any crisis situation [28].

Paraskevas [28], Quek, McManus [34], Vargo and Stephenson [35], report that several models of organizational resilience have been proposed (e.g.), taking into account high levels of situational awareness, the ability to manage vulnerability pitfalls through planning, and the ability to adapt to emerging situations as key resilience factors. Within these factors, elements of learning, risk identification, vulnerability assessment, proactive posture, planning strategies, and recovery priorities are proposed as key indicators of resilience. McManus, Sevilla, Vargo, and Brunsdon [36], define organizational resilience as " . . a function of an organization's overall situation awareness, management of keystone vulnerabilities and adaptive capacity in a complex, dynamic and interconnected environment".

Process safety is identified as an integral part of process development and production as a "complement" to the process, and distinguishes it from occupational safety by focusing mainly on preventive activities and mitigating the consequences of major accidents such as fires, explosions, or leaks of hazardous substances. Process safety assessment consists of basic steps such as identification, analysis, evaluation, and risk management [2,37].

One of the tools for increasing the security of Industry 4.0 companies is the implementation of crisis management into management systems. Crisis management is currently being used on an increasingly large scale. In addition to the initial focus on crises caused by natural and industrial disasters [38,39] and response and recovery capabilities, researchers are increasingly concerned about crises caused by terrorist acts [40], cyber-attacks [41,42]. Additionally, the interdependence between critical infrastructures [43], the examination of a more comprehensive approach to disaster risk reduction $[37,44,45]$, and the need to adapt to climate change [46-48].

Crisis management, especially in the manufacturing sector, can change the distinction between widespread and costly downtime and rapid resumption of operations [49]. The examination of major accidents and crises in the real world confirms that most of them occurred due to the poor quality of crisis management systems [50]. Numerous studies suggest that highly reliable organizations are able to prevent crises. Other factors, including organizational culture and structure, may affect the likelihood of a crisis. It can be assumed that cultural and structural factors increasing the likelihood of a crisis also make it difficult to organize reliability [51]. Barton [52], Coombs with Laufer [53], argue that organizations are better able to manage crises when they have a crisis management plan that is updated at least once a year, have a dedicated crisis management team, carry out exercises to test plans and teams to prepare some crisis reports at least once a year and in advance.

Both security and sustainability perceived in the context of Industry 4.0 emphasize the protection and development of society (people), the economy and the environment (ecology), in which advances in security can be further extended to overcome the operational shortcomings of sustainable development. We try to point this out in our study, where we 
want to emphasize the importance of using the software as an aid in crisis management. Our contribution builds on the research carried out by Nawaz [54], which points out that studies perceive the role of security in achieving the goals of sustainable development. However, practical examples from the given issue are missing e.g., there are only three articles that have used the case study to demonstrate that the interrelationship between security and sustainability can no longer be ignored [55-57].

Although industry and experts recognize the link between security and sustainability, they are usually not taken into account at the strategic and operational levels. The main reason for ignoring this basic relationship is the lack of a safety culture. The global security culture in companies and organizations has not developed as expected; safety is still considered a burden until an accident occurs. A safety culture is particularly important in companies because it encourages risk-based thinking at all levels, which subsequently helps to capture development opportunities through risk management and risk minimization. Without culture, it is not possible to realize the benefits of the relationship between security and sustainability. In fact, it is difficult to achieve sustainability unless a culture of collective progress develops. No process can be sustainable unless it is safe [53]. Crisis managers use various simulations to increase security, so they can anticipate possible negative impacts.

For risk assessment, there are many methods and tools. In determining risk zones, different software is used for modeling release and the subsequent dispersion of hazardous materials (for example ALOHA, TerEx, ROZEX). These software have different settings of input parameters and give different outputs. A major deficiency of these programs is that the calculations simulate the leak of the substance only to an open space. This means that if the source of leakage is in the building, the program does not impede the inhibit ability of immediate dispersion of the building of a hazardous substance into the exterior (open space). Modeling results are then distorted and danger zones are greater than necessary. The result of all these facts is, that the operator of the company included the danger protocols based on the results of risk assessment, such as having to invest a great amount of funds to security measures; still, the real environment threat is significantly smaller than calculated. It is this software that takes into account the direction of the wind, so it is possible to create scenarios for all wind directions, and thus directly determine its impact on the environment [58]. This software is used in various areas where there is a risk of leakage of hazardous substances. It has also been used in various studies, whether in large industrial plants or in the transport of dangerous goods itself $[59,60]$. There is also a risk of leakage during transport via various pipes. If the pipeline is damaged, harmful and hazardous substances can escape into the environment. This problem was simulated using ALOHA software by several authors [61-63]. In the simulation, they assumed a direct leakage of the substance and did not consider the possibility that the spread of substances would slow down or prevent such pipelines being underground or passing through an enclosed space. The program did not allow them to anticipate a case of initial leakage into an enclosed space and only then a possible leak into the space.

Other examples of leaks of hazardous substances have occurred directly in the various areas where they are handled. Some authors have pointed to the possibility of escape in the event of large-scale fires or explosions of the building. With simulations, they did not take into account the possibility of explosion and fire of only one element in the building $[59,64]$. In such a case, the substances would first escape into the enclosed space and later into the environment. Other research has focused on the current problem of electric cars, where a charging accident may occur. Research has focused on charging stations, in the event of an accident, substances leak directly into the outside environment [65]. There are many stations that are in closed buildings (garages), which is why the software interface should be supplemented by the ability of buildings to slow down the spread of hazardous substances. Currently, the most common use of ALOHA software is in the simulations case of leakage of hazardous substances from tanks, where the substance leaks directly into the open air [66,67]. 
There is a simulation of leakage of hazardous substances into another enclosed environment. The simulation is associated with hydrocarbons. Leakage occurs into individual barriers, which had the task of preventing the leakage of substances into the external environment [68]. Other authors also use the simulation of ammonia leakage using ALOHA software. The disadvantage is that they only consider the possibility of escaping directly into open space [69]. The results obtained by the products are designed to ensure emergency planning responses for crisis managers, individuals near accident sites, and residents in order to reduce potential risks [70]. Therefore, it is necessary to pay attention to simulation not only in the transport of dangerous goods, but especially in potential leakage from companies. Based on simulations and modeling, these companies are often considerable resources for preventing various negative events.

In many articles that we studied during the preparation of the article, the authors focus on modeling the leakage of hazardous substances in the gaseous state, and all modeling is carried out in the just mentioned way, directly into the air. None of the authors take into account that part of the substance may be trapped in other surrounding areas and thus create a barrier to the leaked substance. It is with our contribution that we want to open a space for discussion and consideration of adding scenarios to modeling, which would take into account the given facts and thus help create real scenarios in which security and financial demands will be balanced.

The main article addresses as a main goal the comparison of a conservative approach to the modeling of leakage of hazardous substances, where, based on illustrative examples, it explains the procedure of individual approaches. Modeling of leakage of hazardous substances within civil protection in Slovakia is calculated with immediate leakage of the total amount of hazardous substance, i.e., when we have a container with a hazardous substance in a building, for example $\left(\mathrm{NH}_{3}\right.$ or $\left.\mathrm{Cl}_{2}\right)$, the result is calculated as the maximum amount substances from this tank. Distances that are not realistic, elevated, and distances that are too pessimistic are plotted on the map. While this is on the security side, on the other hand, security costs are rising enormously.

The approach we outline in the article shows us the possibilities of how we can create more realistic estimates so that we do not endanger the safety of the population but, on the other hand, do not increase unnecessarily costs. This creates space to take into account the amount of hazardous substance that will be retained in the interior of the building in which the tanks are located.

\section{Materials and Methods}

\subsection{The Ability of a Building to Prevent the Dispersion of Dangerous Materials}

The ALOHA CAMEO software was used by the authors, it is the most frequently used software in the field of crisis management, prevention of serious industrial accidents, and civil protection in the Slovak Republic. Based on a literary analysis, we pointed out that it was also used by many authors in the world. In addition, the software is freely available and the authors have used it in practice to identify hazards from gaseous hazardous substances. Due to the freely available software, it can be used free of charge by crisis managers in all companies where there is a risk of dispersion of hazardous substances.

In our example, ALOHA software was used to model the leakage of a hazardous substance. We modeled the leakage of a hazardous substance from a $3000 \mathrm{~m}^{3}$ tank; in the first example, we can see the values and the course of the leakage of the immediate leakage of the total amount of the entered substance. The case we mentioned is from a security point of view. This means that we can preventively protect large areas that are endangered after the modeling result. Of course, the costs are rising, as we can see in Figure 1. The concentrations that occur here are very high. Essentially, the concentration increases to about $2390 \mathrm{ppm}$ within ten minutes. This is a concentration that is referred to as outdoor concentration, i.e., outside the building. It does not take into account here at all that the building captures some part of the hazardous substance and thus delays its dispersion within the outdoor spaces. Thus, a model with direct and immediate release 
directly into the air, i.e., an immediate increase in concentration in the whole environment, is considered. This prediction is commonly used in civil protection with this software. However, if we realistically reflect the course of the described accident, we can imagine that after the leakage of the hazardous substance NH3 from the $3000 \mathrm{~m}^{3}$ storage tank within a building, the concentration in the building will increase rapidly. It only slowly gets further out of the building through the ventilation openings of leaks, i.e., windows, doors, and other technical and technological openings.

In order to take into account precisely this fact that the building will capture a certain amount of dangerous substance, we had to take into account the air exchange in the room. Therefore, we recalculated the volume of air in the room, where we took into account the ventilation speed. The air exchange is calculated on the basis of ventilation, in the considered object we have ventilation natural through window and door openings and forced by fans. The result of ventilation is the exchange of the entire volume of air in the room 4 times per hour. This parameter then enters the modeling in the ALOHA program, where the rate of leakage and capture of the substance by the object is considered. The result is Figure 2, where we see that the concentration already in the calculation, taking into account the capture of the atmosphere, shows an increase in concentration within the first ten minutes to a maximum of $898 \mathrm{ppm}$, which is a big difference compared to the first method. Logically, we can deduce that the distance in the exterior of the object to which the concentration will reach will be significantly reduced.

If the source of hazardous material is in the building, we can assume that the spillage is firstly dispersed in premises of the building, not directly into the atmosphere. There, it is mixed with air and only then escapes through holes and leaks in to the exterior atmosphere.

In the case of a leakage in the building, the authors' contribution is based on these considerations:

The whole contents of the hazardous material leak out immediately. The hazardous material released has a specific character, which means this material is either in its gas form, or (if in its liquid form) has a low boiling point, so that the substance vaporizes in the current conditions in a very short time.

If a leaks occur, substance (hazardous material) will expand from a compressed state or evaporate, and therefore, there is an increase in the total volume of gas (air) in the building by the amount of this gas:

$$
V_{W}=V_{A}+V_{H M}\left[\mathrm{~m}^{3}\right]
$$

where:

$V_{W}$ is whole volume of gas in the building,

$V_{A}$ is air volume in the building before leakage of hazardous materials,

$V_{H M}$ is hazardous materials volume in gas phase.

The next consideration for a simplified calculation is that the hazardous material is evenly mixed with the air, and the volume of this mixture exceeds the volume of the space inside the building. Based on this assumption, the authors infer that the mixture leaks out of the building through holes and ventilation systems. The total amount of substance which was released in a very short time from the building and creates the escape called "Puff" is therefore:

$$
V_{P U F F}=V_{H M} \frac{V_{H M}}{V_{W}}\left[\mathrm{~m}^{3}\right]\left[\mathrm{m}^{3}\right] .
$$

The fraction $V_{H M} / V_{W}$ deals with the complex content of hazardous substance in the total mixture with air made inside the building and partially escapes. This amount is very conservative, because since the escape and expansion will push clean air out first, as it is closer to the ventilation holes. In other words, it is possible to say that the real release of hazardous material into the air outside the building will be much smaller.

The remaining amount of hazardous material, which persists inside the building after the initial leak (PUFF), will leak through natural ventilation of this building. This means 
that the volume of leaks over time will be equal to time of exchange of whole air volume in the building. This type of escape is constant, and is called "continuous release":

$$
V_{\text {CONST }}=V_{H M}-V_{P U F F}\left[\mathrm{~m}^{3}\right]\left[\mathrm{m}^{3}\right] .
$$

The overall process is to release a combination of both phenomena.

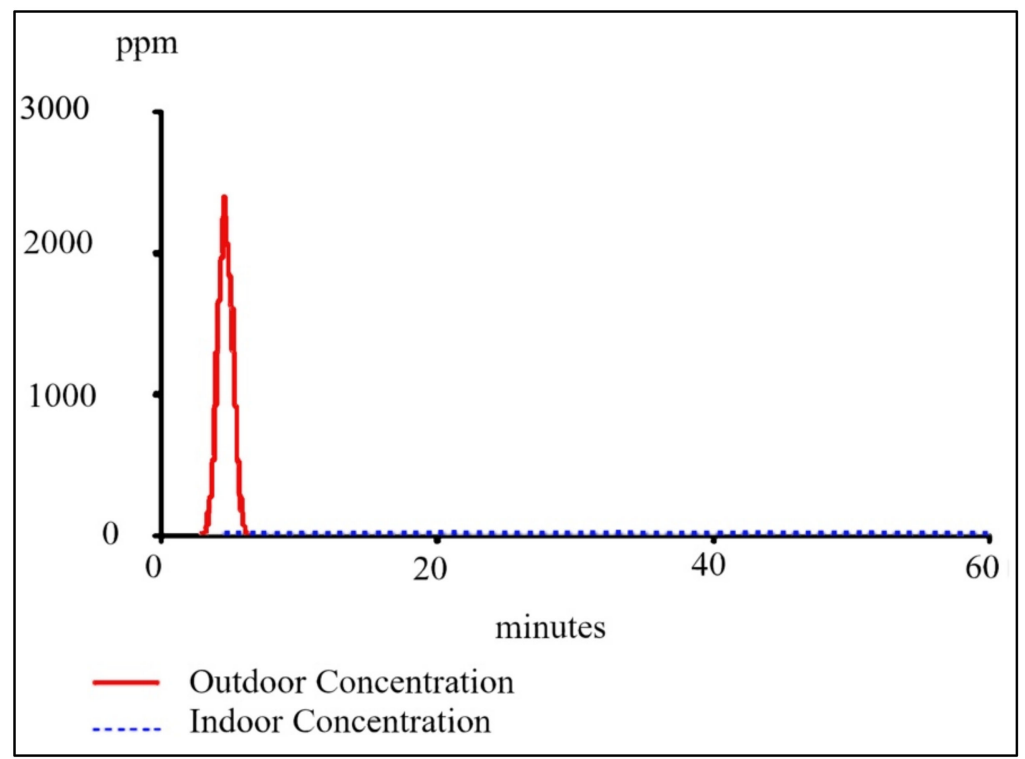

Figure 1. Ammonia concentration against time after leakage off all amounts at once [71].

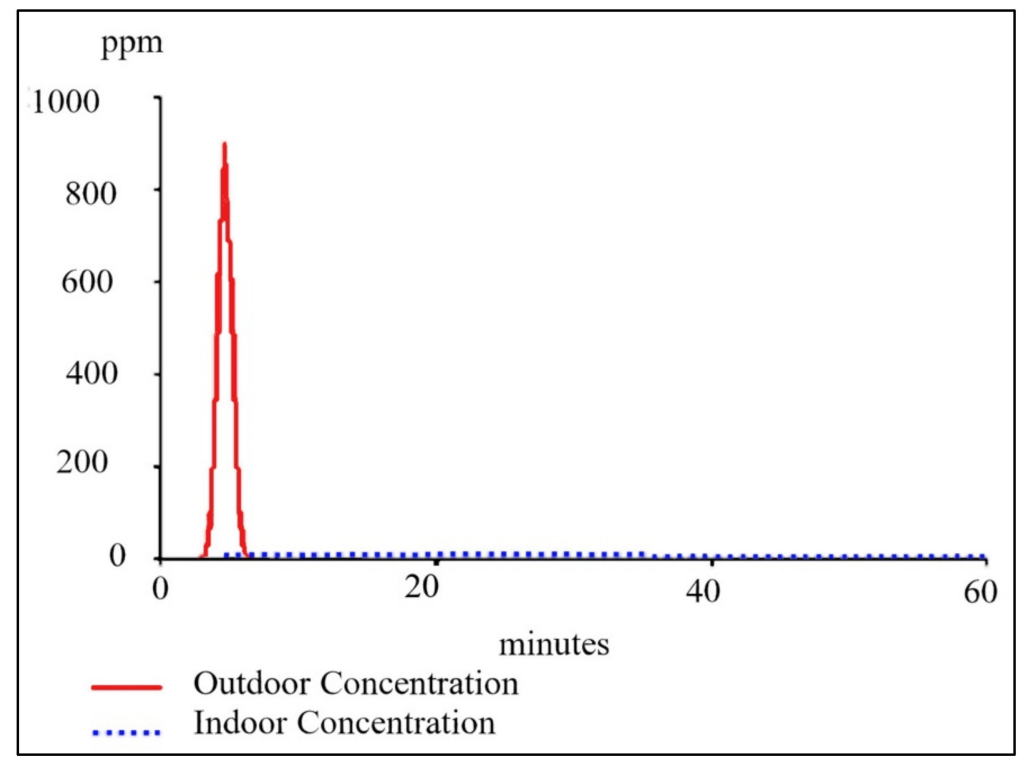

Figure 2. Ammonia concentrations against time after leakage of volume $V_{P U F F}[71]$.

\subsection{Addressing a Model Situation}

For the model situation, a factitious company with a cooling technology, using ammonia as the coolant, was selected. This technology was placed in a closed, separate building-inside a cooling machine room with the total volume of $5000 \mathrm{~m}^{3}$. As for the largest potential source of danger, the reservoir with the capacity of $3000 \mathrm{~m}^{3}$ of ammonia was selected. The building and technology parameters correspond with typical, common installations in the industry, where cooling technologies are used. The studied subject was finding the concentration of the toxic cloud at a fixed distance from the source of leakage. 
For the modeling of dispersion, ALOHA software version 5.4.7 was used. Table 1 lists the input data, which was used as a base in modeling.

Table 1. Input data for modeling leakage at a normal pressure [71,72].

\begin{tabular}{|c|c|}
\hline \multicolumn{2}{|c|}{ Basic Information } \\
\hline Hazardous substance & Ammonia \\
\hline The temperature of the substance & Ambient \\
\hline Pressure & atmospheric \\
\hline Quantity & $3000 \mathrm{~m}^{3}$ \\
\hline Initial event & Full-installation immediately destroys the brain \\
\hline Phase leakage & Gas \\
\hline Location tracking of concentration & $500 \mathrm{~m}$ from the source \\
\hline \multicolumn{2}{|c|}{ Atmospheric Data } \\
\hline Air temperature & $20{ }^{\circ} \mathrm{C}$ \\
\hline Wind speed & $2 \mathrm{~m} / \mathrm{s}$ \\
\hline Stability Class & $\mathrm{D}$ \\
\hline Cloudiness & Partly Cloudy \\
\hline Humidity & $50 \%$ \\
\hline The amount of hole leakage & $0 \mathrm{~m}$ \\
\hline
\end{tabular}

Input dates (pressure and temperature) do not reflect the reality, but in this case, they do not affect the result in the context of the intention of this article. It might be appropriate to discuss the amount of leakage, as it has a significant impact on the outcomes of modeling. It depends on the location of the holes in the building, through which hazardous materials may escape. In our case, zero was chosen, because it represents the most adverse situation.

The classic way allows for immediate and total amount of leakage of hazardous material. The second way is untraditional (alternative), and it takes into account the ability of the building to prevent immediate dispersion to the surrounding environment.

\section{Results of Modeling}

3.1. The Classic Method (Without the Inclusion of Reserve of Hazardous Materials in the Building)

Table 2 shows the results of modeling hazardous material leakage with the current method (leakage of all amounts at once).

Table 2. Outputs from modeling the classic method (500 m) [71].

\begin{tabular}{cc}
\hline Type of Release & Immediate \\
\hline The amount of spillage & $3000 \mathrm{~m}^{3}(100 \%)$ \\
The average rate of leakage & $37.7 \mathrm{~kg} / \mathrm{s}$ \\
Max. duration of brain & $1 \mathrm{~min}$ \\
Max. concentration in air & $2390 \mathrm{ppm}$ \\
Max. concentration in buildings & $23.1 \mathrm{ppm}$ \\
\hline
\end{tabular}

Figure 1 depicts the course of ammonia concentration versus time at a distance of $500 \mathrm{~m}$ from the source of leakage.

As it is obvious from Figure 1, the concentration increased and decreased back to its maximum in the outdoor environment within $10 \mathrm{~min}$. The concentration in the building remained relatively low throughout the monitored time. The maximum concentration here reached values around $2390 \mathrm{ppm}$ in the case of calculations that were performed in the classical way. However, for the possibility of a more realistic display, it is appropriate to apply a new method, in which the object is expected to retain a certain amount of the hazardous substance. 


\subsection{Alternative (Proposed) Method}

After solving the above formulas number $1-3$, the authors obtained the value of the quantity of ammonia leaked from the building:

$$
\begin{gathered}
V_{\text {PUFF }}=1125 \mathrm{~m}^{3}, \\
V_{\text {CONST }}=1875 \mathrm{~m}^{3} .
\end{gathered}
$$

The results for modeling by the second method (alternative) are depicted in Table 3 , which consider the ability of the building to prevent immediate dispersion to the surrounding environment.

Table 3. Output data of modeling considering the ability of building to prevent immediate dispersion of ammonia $(500 \mathrm{~m})$ [71].

\begin{tabular}{ccc}
\hline Type of Release & Puff & Constant \\
\hline The amount of spillage & $1125 \mathrm{~m}^{3}(37.5 \%)$ & $1875 \mathrm{~m}^{3}(62.5 \%)$ \\
The average rate of leakage & $14.2 \mathrm{~kg} / \mathrm{s}$ & $94.4 \mathrm{~kg} / \mathrm{m}$ \\
Max. duration of release & $1 \mathrm{~min}$ & $15 \mathrm{~min} *$ \\
Max. concentration in air & $898 \mathrm{ppm}$ & $126 \mathrm{ppm}$ \\
Max. concentration in buildings & $8.64 \mathrm{ppm}$ & $13.7 \mathrm{ppm}$ \\
\hline
\end{tabular}

* Value corresponds to the exchange of air in the boxes away and transverse ventilation (4 times per hour) [73].

According to the calculations given in Part 2 of this article, it can be seen that the value of the leaked substance was calculated according to the presented rules, taking into account the internal volume of the building in which the substance is located, as well as the ventilation rate. This way, it is possible to calculate the leakage of a hazardous substance in the gaseous state in a more detailed, and thus more realistic way.

Figure 2 describes the so-called puff effect, where we consider the immediate release of a given hazardous substance. Figure 3 shows the course of ammonia concentration against time at a distance of $500 \mathrm{~m}$ from the source of leakage.

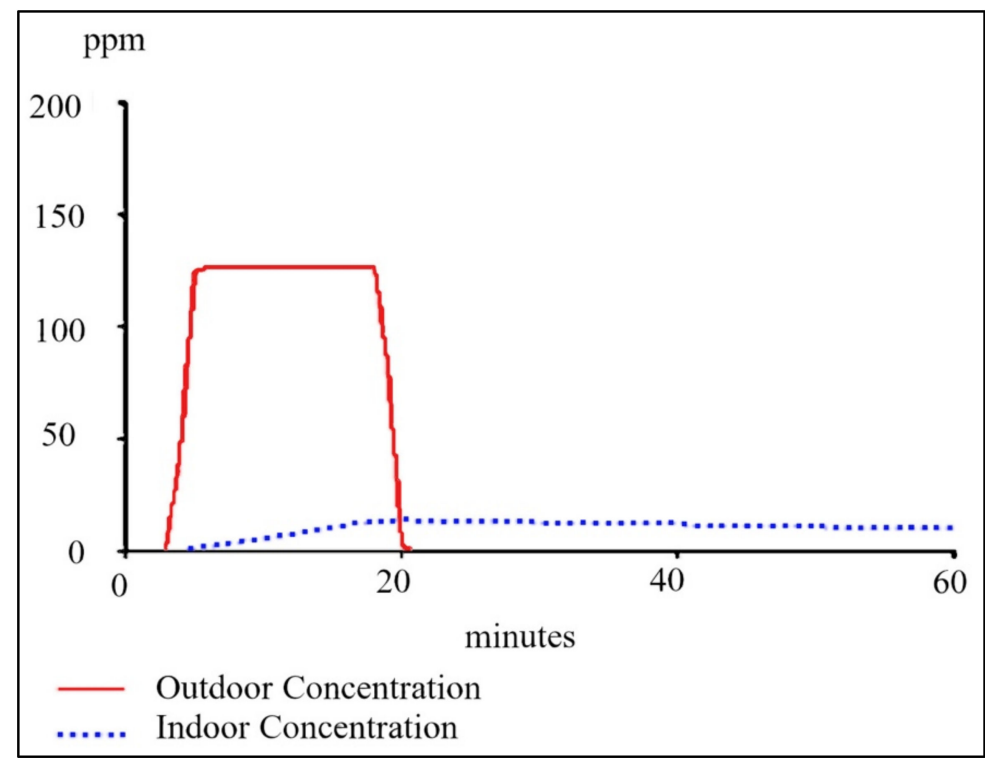

Figure 3. Ammonia concentrations against time after leakage of volume $V_{\text {CONST }}$ [71].

In Figure 2, immediate leakage is counted with, which can be expected at $37.5 \%$ of the substance. In Figure 3, the course of concentration in time is measured after retention of the object. This is a constant leak lasting $15 \mathrm{~min}$ (according to the volume and air exchange in the building). 
In our case, we got the values that we can see in Table 3. The advantage of the alternative approach is that the concentrations achieved are more realistic. If the first case reached a maximum of about 2390, the alternative gives a maximum concentration of $898 \mathrm{ppm}$ and $126 \mathrm{ppm}$. The course of concentrations is different in the case of puff leakage and constant leakage. It is depicted in Figure 2 that during a puff leak, there is an immediate increase in concentration to a maximum, followed by a rapid decrease. This whole process takes less than $10 \mathrm{~min}$.

In Figure 3, you can see the result of modeling for a constant leakage, which lasted a certain time; in our case, it is a 20-min course of gradually escaping ammonia. The concentration that is in the vicinity has significantly decreased, i.e., if we looked at the results of modeling with a constant leakage quite realistically, we would reach a maximum concentration in the outdoor area of 126 ppm.

However, in the case of a constant leak, an increase and stagnation of the maximum concentration can be observed for approximately $20 \mathrm{~min}$ after the leak. This is mainly due to the fact that the leak lasted $15 \mathrm{~min}$, and its spread was slower. Although lower concentrations of a hazardous substance are achieved here, elevated concentrations occur over a longer period of time, which may pose an additional risk that needs to be recognized.

\section{Discussion}

If the second method (alternative) is used, it is necessary to take in account that modeled losses (puff and constant) will follow immediately behind, so the resulting concentrations will operate simultaneously. Therefore, if we want to obtain a final concentration of the place, these values have to be added up. Thus, the calculated concentration can be used only for concentrations of hazardous material in the air. Calculations of concentration in building are complicated and not the content of this article. So, when we finally compare all the modeled approaches by the classical conservative approach, we get to the value of the ammonia concentration of $2390 \mathrm{ppm}$ in the exterior. At the same time and in the same space, in our alternative method, we reach a concentration of 1024 ppm as shown in Table 4 . The result figure will then look as follows.

Table 4. Output data from modeling-summary.

\begin{tabular}{ccc}
\hline Method of Modeling & Classic & Alternative \\
\hline Concentration in air & $2390 \mathrm{ppm}$ & $1024 \mathrm{ppm}$ \\
\hline
\end{tabular}

If ammonia concentrations in the atmosphere were to be reflected in a chart (Figure 4), it is clear to see that the final concentration is significantly lower using the alternative way of modeling.

The issue of safety nowadays has a great importance attached to it, but on the other hand, there is an equally great effort to save as much as possible on prevention costs. That is why the search for compromises is a great challenge. One of such compromises is the proposed approach. As seen in the outputs, it preserves safety but reduces the cost of prevention, precisely because of the detailed assessment of the linkage processes in the building.

This paper outlined the importance of crisis prevention and security in Industry 4.0. The industry is very dynamic and prone to change. Further research is needed into the use of appropriate crisis prevention tools not only at the operational level but also at the strategic management level. Jasiulewicz-Kaczmarek et al. [74], performed a thorough literature analysis, which dealt with the use of various data in Industry 4.0. In this analysis, pointing to the use of a data-based maintenance approach creates many new opportunities to improve maintenance processes. Among the potential benefits that can be considered, improves environmental safety and improves worker safety. 


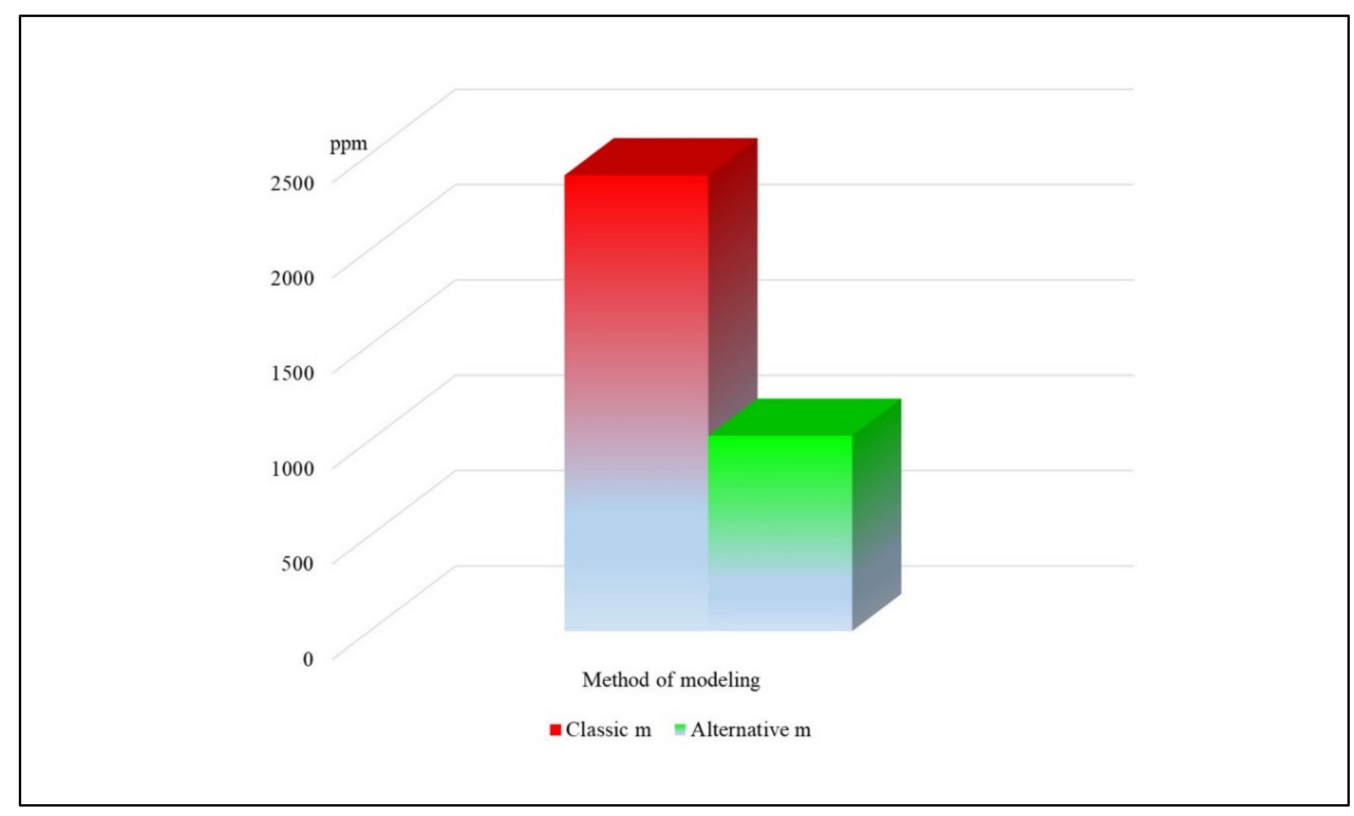

Figure 4. Diagram of the resulting concentrations.

In order for the ALOHA software to be used correctly in some companies, it is necessary to supplement it with the data that we pointed out in the article. It is the new calculations, which are based on additional data, that enable companies to correctly create the conditions for an adequate response in the event of a leak of hazardous substances. In addition, such a response will reduce the negative impact on the environmental environment, the lives and health of the population in the vicinity of such a company, and, last but not least, the lives and health of employees and people in the company. Therefore, it is important that the software is used with such data, which helps to eliminate its shortcomings, and it is modern companies that should take into account as much data as possible. Crisis managers should continue to work with these data and use them to eliminate unnecessary costs for the company caused by incorrect modeling of the release of hazardous substances.

In this way, crisis managers prepare the company for an adequate response and at the same time can save it money by more accurately identifying the negative impact of crisis situations in the company. The use of relevant software serves crisis managers to support decision-making and also allows them to minimize financial costs, reduce response time, and positively influence crisis management in the company [75].

\section{Conclusions}

The article suggests a possible solution to remove the knowledge gap of programs for modeling of the releases of hazardous materials and their concentrations. Using an alternative method may be preferred to achieve more objective results of modeling, which can be favorably compared with the standard method of modeling. A possible drawback of this method is that it can be used only for losses of hazardous materials in the gas phase, and only for modeling of a direct leakage into the environment. Another big disadvantage is that no modifications or additional software calculations can fix the difficulties the program has with determining the distance of the concentration from the source of the leakage (e.g., determining the hazard zone). In a simplified form, this can be solved using systematic commissioning distances until the desired level is achieved, but this process can get lengthy. It is the improvement of tools for the prevention of industrial accidents and, thanks to the proposed solution, the creation of real scenarios that is one of the possible directions of development within Industry 4.0.

Thanks to the obtained results, the situation changes significantly not only for the company but especially for the surroundings of the company in which the substance is located. Thanks to the alternative method we proposed in the article, investors and 
business owners can save large financial costs. It is also very beneficial for spatial planning, where relatively large areas at risk from businesses, calculated in a conservative way, can be withdrawn almost halfway thanks to an alternative approach. So, instead of a radius of $800 \mathrm{~m}$ of the endangered area, we can talk about an area of $500 \mathrm{~m}$ and the like. For civil protection, space is opening up for the accurate preparation of the population, the information and preparation for self with fewer vulnerable persons.

Author Contributions: Conceptualization, M.P., J.K., P.D., K.P., K.R.S. and K.B.; methodology, M.P., J.K., P.D., K.P., K.B.; software, M.P., P.D. and J.K.; validation, M.P., J.K., P.D., K.P., K.R.S. and K.B; formal analysis, M.P., J.K., P.D.; investigation, M.P., J.K., P.D., K.P., K.R.S. and K.B.; resources, M.P., J.K., P.D., K.P., K.B.; data curation, M.P., J.K., P.D., K.P.; writing-original draft preparation, M.P., J.K., P.D., K.R.S. and K.B.; writing-review and editing, M.P., J.K.; supervision, J.K, M.P.; project administration, J.K., K.R.S.; funding acquisition, J.K., K.R.S., K.B. All authors have read and agreed to the published version of the manuscript.

Funding: This research received no external funding.

Institutional Review Board Statement: Not applicable.

Informed Consent Statement: Not applicable.

Data Availability Statement: Data is contained within the article.

Acknowledgments: This paper was supported by project Grant System of University of Zilina No. 8011/2020, by project KEGA 043ŽU-4/2019 and by project KEGA 026ŽU-4/2020.

Conflicts of Interest: The authors declare no conflict of interest.

\section{References}

1. Pech, M.; Vrchota, J. Classification of Small- and Medium-Sized Enterprises Based on the Level of Industry 4.0 Implementation. Appl. Sci. 2020, 10, 5150. [CrossRef]

2. The Concept of Intelligent Industry for Slovakia. Available online: https://www.mhsr.sk/inovacie/strategie-a-politiky/smartindustry (accessed on 17 September 2020).

3. Kiel, D.; Müller, J.; Arnold, C.; Voigt, K.-I. Sustainable Industrial Value Creation: Benefits and Challenges of Industry 4.0. Int. J. Innov. Manag. 2017, 21, 1740015. [CrossRef]

4. Gibson, R. Beyond the Pillars: Sustainability assessment as a framework for effective integration of social, economic and ecological considerations in significant decision-making. J. Environ. Assess. Policy Manag. 2006, 8, 259-280. [CrossRef]

5. Sridhar, K.; Jones, G. The three fundamental criticisms of the Triple Bottom Line approach. An empirical study to link sustainability reports in companies based in the Asia-Pacific region and TBL shortcomings. Asian J. Bus. Ethics 2013, 2, 91-111. [CrossRef]

6. Sangwan, S.R.; Bhatia, M.P.S. Sustainable Development in Industry 4.0. In A Roadmap to Industry 4.0: Smart Production, Sharp Business and Sustainable Development; Advances in Science, Technology \& Innovation; Anand, N., Akshi, K., Eds.; Springer: Cham, Switzerland, 2020; pp. 39-56.

7. Müller, J.M.; Kiel, D.; Voigt, K.-I. What Drives the Implementation of Industry 4.0? The Role of Opportunities and Challenges in the Context of Sustainability. Sustainability 2018, 10, 247. [CrossRef]

8. Brettel, M.; Friederichsen, N.; Keller, M.; Rosenberg, M. How Virtualization, Decentralization and Network Building Change the Manufacturing Landscape: An Industry 4.0 Perspective. Int. J. Mech. Aerosp. Ind. Mechatron. Eng. 2014, 8, 37-44.

9. Hansen, E.G.; Grosse-Dunker, F.; Reichwald, R. Sustainability innovation cube-A framework to evaluate sustainability-oriented innovations. Int. J. Innov. Manag. 2009, 13, 683-713. [CrossRef]

10. Çınar, Z.M.; Abdussalam Nuhu, A.; Zeeshan, Q.; Korhan, O.; Asmael, M.; Safaei, B. Machine Learning in Predictive Maintenance towards Sustainable Smart Manufacturing in Industry 4.0. Sustainability 2020, 12, 8211. [CrossRef]

11. Kamble, S.; Gunasekaran, A.; Dhone, N.C. Industry 4.0 and lean manufacturing practices for sustainable organisational performance in Indian manufacturing companies. Int. J. Prod. Res. 2020, 58, 1319-1337. [CrossRef]

12. Kagermann, H. Change through digitization-Value creation in the age of Industry 4.0. In Management of Permanent Change; Albach, H., Meffert, H., Pinkwart, A., Reichwald, R., Eds.; Springer Gabler: Wiesbaden, Germany, 2015; pp. $23-45$.

13. Tureková, I.; Gašpercová, S.; Brečka, P.; Valentová, M. Risk management applied in terms of practical training at university. In Proceedings of the 11th International Technology, Education and Development Conference, INTED 2017, Valencia, Spain, 6-8 March 2017; pp. 465-475.

14. Grabowska, S.; Gajdzik, B.; Saniuk, S. The role and impact of industry 4.0 on business models. In Sustainable Logistics and Production in Industry 4.0. New Opportunities and Challenges; Grzybowska, K., Awasthi, A., Sawhney, R., Eds.; Springer: New York, NY, USA, 2020; pp. 31-50. 
15. Machado, C.G.; Winroth, M.P.; Ribeiro da Silva, E.H.D. Sustainable manufacturing in Industry 4.0: An emerging research agenda. Int. J. Prod. Res. 2020, 58, 1462-1484. [CrossRef]

16. Gobbo, J.A.; Busso, C.M.; Gobbo, S.C.O.; Carreão, H. Making the links among environmental protection, process safety, and industry 4.0. Process Saf. Environ. Prot. 2018, 117, 372-382. [CrossRef]

17. Tupa, J.; Simota, J.; Steinar, F. Aspects of Risk Management Implementation for Industry 4.0. Procedia Manuf. 2017, 11, 1223-1230. [CrossRef]

18. Elattar, S.; Abed, A.M.; Alrowais, F. Safety Maintains Lean Sustainability and Increases Performance through Fault Control. Appl. Sci. 2020, 10, 6851. [CrossRef]

19. Folch-Calvo, M.; Brocal-Fernández, F.; González-Gaya, C.; Sebastián, M.A. Analysis and Characterization of Risk Methodologies Applied to Industrial Parks. Sustainability 2020, 12, 7294. [CrossRef]

20. Qiao, W.; Member, S.; Lu, D.; Member, S. A Survey on Wind Turbine Condition Monitoring and Fault Diagnosis-Part I: Components. IEEE Trans. Ind. Electron. 2015, 62, 6536-6545. [CrossRef]

21. Jasiulewicz-Kaczmarek, M.; Gola, A. Maintenance 4.0 Technologies for Sustainable Manufacturing-An Overview. IFAC-PapersOnLine 2019, 52, 91-96. [CrossRef]

22. Öcal, E.; Laptali, E.; Erdis, E. Crisis management in Turkish construction industry. Build. Environ. 2006, 41, 1498-1503. [CrossRef]

23. Ritchie, B.W. Chaos, crises and disasters: A strategic approach to crisis management in the tourism industry. Tour. Manag. 2004, 25, 669-683. [CrossRef]

24. Darling, J.; Hannu, O.; Raimo, N. Crisis management in international business: A case situation in decision making concerning trade with Russia. Finn. J. Bus. Econ. 1996, 4, 12-25.

25. Burnett, J.J. A strategic approach to managing crises. Public Relat. Rev. 1998, 24, 475-488. [CrossRef]

26. Kash, T.J.; Darling, J. Crisis management: Prevention, diagnosis and intervention. Leadersh. Organ. Dev. J. 1998, 19, 179-186. [CrossRef]

27. Heath, R. Crisis management for managers and executives. In Financial Times Management; Pitman Publishing: London, UK, 1998.

28. Paraskevas, A.; Quek, M. When Castro seized the Hilton: Risk and crisis management lessons from the past. Tour. Manag. 2019, 70, 419-429. [CrossRef]

29. Rosenthal, U.; Kouzmin, A. Crises and Crisis Management: Toward Comprehensive Government Decision Making; Leiden University: Leiden, The Netherlands, 1997.

30. Van Wart, M.; Kapucu, N. Crisis management competencies: The case of emergency managers in the USA. Public Manag. Rev. 2011, 13, 489-511. [CrossRef]

31. Sanchez, E.Y.; Acquesta, A.A. CRISIS: A System for Risk Management. Systems 2013, 1, 3-26. [CrossRef]

32. Tagarev, T.; Ratchev, V. A Taxonomy of Crisis Management Functions. Sustainability 2020, 12, 5147.

33. International Organization for Standardization. Societal Security_Preparedness and Continuity Management Systems—Requirements; ISO 22301:2012; International Organization for Standardization: Geneva, Switzerland, 2012.

34. McManus, S. Organisational Resilience in New Zealand; University of Canterbury: Christchurch, New Zealand, 2007.

35. Vargo, J.; Stephenson, A.V. Measuring organizational resilience. In Proceedings of the 20th World Conference on Disaster Management, Toronto, ON, Canada, 20-23 June 2010.

36. McManus, S.; Seville, E.; Vargo, J.; Brunsdon, D. A facilitated process for improving organizational resilience. Nat. Hazards Rev. 2008, 9, 81-90. [CrossRef]

37. Hollá, K.; Moricová, V. Specifics of Monitoring and Analysing Emergencies in Information Systems. In Proceedings of the 13th International Scientific Conference on Sustainable, Modern and Safe Transport (TRANSCOM 2019), Žilina, Slovakia, 29-31 May 2019; Volume 40, pp. 1343-1348.

38. Titko, M.; Ristvej, J. Assessing Importance of Disaster Preparedness Factors for Sustainable Disaster Risk Management: The Case of the Slovak Republic. Sustainability 2020, 12, 9121. [CrossRef]

39. Zánická Hollá, K.; Ristvej, J.; Šimák, L. Systematic Method of Risk Assessment in Industrial Processes. WIT Trans. Inf. Commun. Technol. 2011, 43. [CrossRef]

40. Eller, W.S.; Wandt, A.S. Contemporary policy challenges in protecting the homeland. Policy Stud. J. 2020, 48, S33-S46. [CrossRef]

41. Paté-Cornell, M.-E.; Kuypers, M.; Smith, M.; Keller, P. Cyber risk management for critical infrastructure: A risk analysis model and three case studies. Risk Anal. 2018, 38, 226-241. [CrossRef]

42. Stofkova, J.; Maris, L.; Soltes, V. To the Problem of Information Security within the Local Government. In Proceedings of the 7th International Conference on Education and New Learning Technologies (EDULEARN), Barcelona, Spain, 6-8 July 2015; pp. 6629-6635.

43. Sventekova, E.; Luskova, M.; Dvorak, Z. Use of network analysis in conditions of critical infrastructure risk management. In Proceedings of the WMSCI 2016: The 20th World Multi-Conference on Systemics, Cybernetics and Informatics, Orlando, FL, USA, 5-8 July 2016; Volume II, pp. 247-250, ISBN 978-1-941763-43-8.

44. Shaw, D.; Fattoum, A.; Moreno, J.; Bealt, J. A Structured Methodology to peer review disaster risk reduction activities: The viable system review. Int. J. Disaster Risk Reduct. 2020, 46, 101486. [CrossRef]

45. Lee, Y.; Watanabe, K.; Li, W.-S. Public private partnership operational model-A conceptual study on implementing scientificevidence-based integrated risk management at regional level. J. Disaster Res. 2019, 14, 667-677. [CrossRef]

46. Wilkinson, E.; Mysiak, J.; Oliveira, C.S.; Peters, K.; Surminski, S. Managing disaster risk. In Science for Disaster Risk Management 2017: Knowing Better and Losing Less; Poljanšek, K., Ferrer, M.F., De Groeve, T., Clark, I., Eds.; European Commission: Brussels, Belgium, 2017; pp. 442-515. 
47. Booth, L.; Fleming, K.; Abad, J.; Schueller, L.A.; Leone, M.; Scolobig, A.; Baills, A. Simulating synergies between climate change adaptation and disaster risk reduction stakeholders to improve management of transboundary disasters in Europe. Int. J. Disaster Risk Reduct. 2020, 49, 101668. [CrossRef] [PubMed]

48. Owen, G. What makes climate change adaptation effective? A systematic review of the literature. Glob. Environ. Chang. 2020, 62, 102071. [CrossRef]

49. Tokakis, V.; Polychroniou, P.; Boustras, G. Crisis management in public administration: The three phases model for safety incidents. Saf. Sci. 2019, 113, 37-43. [CrossRef]

50. Brezina, D.; Šimák, L.; Hudáková, M.; Masár, M. Application of multicriteria decision-making methods for the optimal evacuation. Transp. Res. Procedia 2019, 40, 963-969. [CrossRef]

51. Bundy, J.; Pfarrer, M.D.; Short, C.E.; Coombs, W.T. Crises and Crisis Management: Integration. Interpret. Res. Dev. J. Manag. 2016, 43, 1661-1692.

52. Barton, L. Crisis in Organizations II College Divisions South-Western; South-Western College Pub: Cincinati, OH, USA, 2001.

53. Timothy Coombs, W.; Laufer, D. Global Crisis Management-Current Research and Future Directions. J. Int. Manag. 2018, 24, 199-203. [CrossRef]

54. Nawaz, W.; Linke, P.; Koç, M. Safety and sustainability nexus: A review and appraisal. J. Clean. Prod. 2019, 216, 74-87. [CrossRef]

55. Hedlund, F.H.; Astad, J. Solid biomass climate change interventions examined in a context of inherent safety, media shifting, and emerging risks. Hum. Ecol. Risk Assess. 2015, 21, 1410-1427. [CrossRef]

56. Lewis, S. LewisLessons on corporate "sustainability" disclosure from deepwater horizon. New Solut. A J. Environ. Occup. Health Policy 2011, 21, 197-214. [CrossRef] [PubMed]

57. Meshkati, N. Lessons of the chernobyl nuclear accident for sustainable energy generation: Creation of the safety culture in nuclear power plants around the world. Energy Sources Part A Recover Util. Environ. Eff. 2007, 29, 807-815.

58. Sanchez, E.Y.; Represa, S.; Mellado, D.; Balbi, K.B.; Acquesta, A.D.; Lerner, J.E.C.; Porta, A.A. Risk analysis of technological hazards: Simulation of scenarios and application of a local vulnerability index. J. Hazard. Mater. 2018, 352, 101-110. [CrossRef]

59. Rajeev, K.; Soman, S.; Renjith, V.R.; George, P. Human vulnerability mapping of chemical accidents in major industrial units in Kerala, India for better disaster mitigation. Int. J. Disaster Risk Reduct. 2019, 39, 101247. [CrossRef]

60. AlRukaibi, F.; Alrukaibi, D.; Alkheder, S.; Alojaiman, S.; Sayed, T. Optimal route risk-based algorithm for hazardous material transport in Kuwait. J. Loss Prev. Process Ind. 2018, 52, 40-53. [CrossRef]

61. Chen, S.Y.; Lin, M.S.; Hsiao, G.L.K.; Wang, T.C.; Kao, C.S. Underground Pipeline Leakage Risk Assessment in an Urban City. Int. J. Environ. Res. Public Health 2020, 17, 3929. [CrossRef]

62. Kalatpoor, O.; Goshtasp, K.; Khavaji, S. Health, Safety and Environmental Risk of a Gas Pipeline in an Oil Exploring Area of Gachsaran. Ind. Health 2011, 49, 209-214. [CrossRef]

63. Chen, H.N.; Mao, Z.L. The study on the results of hydrogen pipeline leakage accident of different factors. Int. Symp. Resour. Explor. Environ. Sci. 2017, 64, 012002. [CrossRef]

64. Ahn, M.S.; Lee, H.E.; Cheon, K.S.; Joo, H.G.; Son, B.S. Feasibility Evaluation of Designated Quantities for Chemicals Requiring Preparation for Accidents in the Korean Chemical Accident Prevention System. Int. J. Environ. Res. Public Health 2020, $17,1927$. [CrossRef]

65. Nuamkoksung, P.; Buayai, K.; Kongjeen, Y.; Bhumkittipich, K.; Kerdchen, K.; Mithulananthan, N. Impact of Fast Charging on Lithium-ion Battery in Electric Vehicle Application. In Proceedings of the 8th International Electrical Engineering Congress (iEECON), Chiang Mai, Thailand, 4-6 March 2020. Book Series: International Electrical Engineering Congress. [CrossRef]

66. Orozco, J.L.; Van Caneghem, J.; Hens, L.; Gonzalez, L.; Lugo, R.; Diaz, S.; Pedroso, I. Assessment of an ammonia incident in the industrial area of Matanzas. J. Clean. Prod. 2019, 222, 934-941. [CrossRef]

67. Mehrabani, M.A.; Ghiyasi, S. Modeling the consequences of accidents during the process of transferring waste thinner from the paint shop of an automotive industry using aloha software. Int. Arch. Health Sci. 2018, 5, 55-61. [CrossRef]

68. Hammouya, A.; Kabouche, A.; Chaib, R. Study of Drain Barrier Effect on Hydrocarbons Hazards. J. Fail. Anal. Prev. 2019, 19, 1475-1486. [CrossRef]

69. Lopes, T.J.; Barros, R.; dos Santos, N.L.; Costelli, M.C.; da Silva, A.; Cancelier, A. Risk Analysis Applied to Industrial Refrigeration Installations that use Ammonia. Rev. Eletron. Gest. Educ. E Tecnol. Ambient. 2015, 19, 160-166. [CrossRef]

70. Jabbari, M.; Atabi, F.; Ghorbani, R. Key airborne concentrations of chemicals for emergency response planning in HAZMAT road transportation- margin of safety or survival. J. Loss Prev. Process Ind. 2020, 93, 103617. [CrossRef]

71. ALOHA Software Version 5.4.7. Available online: http://www.epa.gov/oem/content/cameo/aloha.htm (accessed on 30 October 2020).

72. Actual Weather Information. Available online: http:/ / portal.chmi.cz (accessed on 30 October 2020).

73. Makrowin Ltd. Proper Ventilation. Available online: https://www.makrowin.sk/en/products/proper-ventilation/ (accessed on 30 October 2020).

74. Jasiulewicz-Kaczmarek, M.; Legutko, S.; Kluk, P. Maintenance 4.0 technologies—New opportunities for sustainability driven maintenance. Manag. Prod. Eng. Rev. 2020, 11, 74-87. [CrossRef]

75. Traore, B.B.; Kamsu-Foguem, B.; Tangara, F.; Tiako, P. Software services for supporting remote crisis management. Sustain. Cities Soc. 2018, 39, 814-827. [CrossRef] 